\title{
Racism in the Harry Potter Series
}

\author{
Kaitlin Ollivier-Gooch
}

The cultural phenomenon of the Harry Potter series is one that affected the lives of an entire generation. Countless young adults today were raised alongside Harry Potter, Hermione Granger, and Ron Weasley, learning as they learned. J.K. Rowling accomplished something with her novels that most authors cannot: she created characters that truly grew with the readers. The characters came up against problems of friendship and romance, and wrestled with the concept of death throughout the novels; and, as they dealt with these problems, the readers did too.

One of the prevailing issues dealt with in the Harry Potter novels is racism. There is a very clear othering of many groups in this se- ries; however, the most prominent example by far is the Muggles. Any wizard in the novel who is not Muggle-born or raised by Muggle parents expresses racist tendencies towards Muggles. Despite the fact that the intentions of their actions are spawned from different mentalities, both the 'good' and the 'bad' wizards in the novels are racist, whether expressed through the colonial concept of Orientalism or the negative feelings of xenophobia. The books show that the lines that delimit racist thought and action are not clear, and that being racist is not something for only the 'bad guys'. It also shows readers that racism, while obviously worse when it stems from hatred, is not something that is exclusive to villains in books or in real life, it can affect 
stereotypically good characters as well.

Orientalism is a concept that came from the exploration of foreign cultures. It is defined as an outsider's interpretation of the Orient (Eastern Asia), showing a stereotyped version of the Orient and embodying a colonialist perspective. Orientalism emphasizes the Orient as being different from the West; "a place of romance, exotic beings, haunting memories and landscapes, remarkable experiences" (Said, 1978). It comes from western societies, such as England, as a way to separate themselves from the Orient's cultures and peoples, exoticizing them and seeing them as backwards and uncivilized. While traditionally used to describe the portrayals of the Orient in Western culture, this concept echoes the way that wizards treat and view Muggles in the Harry Potter novels. By applying a concept used in anthropology to review both the novels and literature written on the Harry Potter series, this paper looks more in depth into the themes behind Harry Potter. Most wizards portrayed in the books see Muggles as exotic, less advanced humans who are miraculous in their way of managing to live their lives and accomplish day to day tasks without the use of magic.

The most prominent of the orientalists in the novels is Arthur Weasley. Throughout the novels, he is depicted "as the bewildered British intellectual explorer, both infinitely curious and confused as to the workings of the Muggle world" (Lamb, 2015). He is seen as endearing to the readers, used as comedic relief at times as he is "continually mis-pronouncing the key word to the non-wizarding technology: electricity" (Lamb, 2015). Mr. Weasley is an official at the Ministry of Magic, working in the Misuse of Muggle Artefacts Office. He is championed as one of the most Muggle-sympathetic wizards in the wizarding world, and yet he cannot grasp the concept of the telephone, nor can he do much better than pronounce electricity "eckeltricity" (Rowling, 2000) throughout the novels. Mr. Weasley might be "crazy about everything to do with Muggles" (Rowling, 1998), but he also underestimates their intelligence a number of times throughout the novels. He states that "[Muggles will] go to any lengths to ignore magic, even if it's staring them in the face" (Rowling, 1998), and when explaining Portkeys (objects that can be used to transport individuals from one place to another) he clarifies that they are charmed out of "unobtrusive things, obviously, so Muggles don't go picking them up and playing with them stuff they'll just think is litter" (Rowling, 2000). This illustrates the way that wizards see the Muggles as allowing magic to happen by being ignorant of the more intelligent, purposeful magical world around them. The fact that the person who is the most interested in Muggles, enough to build his career around it, does not understand Muggles in the slightest indicates the way the rest of the wizarding world feels towards Muggles. Mr. Weasley exoticizes the very people he is supposed to be working to protect, mirroring the view of Western colonizers towards their colonies in the Orient.

Like Arthur Weasley, most of the good or neutral wizards view Muggles in an orientalist lens. At the Quidditch World Cup (a large, magical sporting event), the gathering of wizards together takes place in a Muggle campground, so the wizards dress up in 'Muggle clothing' to appear inconspicuous in case any non-wizarding folk are around (Rowling, 2000). When Harry, Hermione and the Weasleys arrive at the campground, they are greeted by a man wearing "a tweed suit with thigh-length galoshes; his colleague, a kilt and a poncho" (Rowling, 2000); very poorly crafted outfits out of Muggle clothing. Wizards are the minority in the world, with knowledge of both the magical and non-magical worlds, and therefore it should not be difficult for those who do not openly oppose Muggles to spend time gaining an understanding of their 'exotic' cultures and customs without having to interact with Muggles. Particularly customs around the way they dress, which are easy to explore through observation, thus eliminating any worry of exposing magic to the Muggles.

Even the Ministry of Magic exists largely to keep magic from non-magical beings, and "the 
wizard's superior abilities and intellect combined with the ineptitude and ignorance of the Muggles" (Lamb, 2015) is what allows the Ministry to, seemingly, do its job successfully. When Cornelius Fudge, the Minster for Magic, speaks to the Muggle Prime Minister about the return of Voldemort, the villain in the novels, it is shown just how much the wizards know about the nature of the attacks and how determined the Muggles are to ignore the presence of magic in their world. Bridges breaking, hurricanes happening in West Country, and mysterious murders are baffling to the Muggle Prime Minister, but he explains them the only way he knows how, the non-magical way, until Fudge tells him the truth (Rowling, 2005). The wizards know exactly what is happening to the world around them, but the Muggles are confused, and their Prime Minister can barely grasp the truth even when it is explained to him. This scene shows the power dynamic between the 'ignorant' Muggle and the 'all-knowing', and sympathetic, wizard. The intentions of most wizards towards Muggles are well-meaning for the most part. However, any wizards who openly despise Muggles are viewed by the main character, and therefore by the readers as an extension of the point of view, as being 'evil' or 'bad'.

Those who do not see Muggles as exotic, blissfully ignorant beings, are the wizards who treat muggles like animals. To these wizards, Muggles are not their equals and therefore deserve to be treated like lesser beings. These pure-blood families, families whose members are all witches and wizards without marrying Muggles, Muggle-borns, or half-bloods, are represented throughout the novels by Draco Malfoy who 'acts as a mouthpiece for his parents' pureblood views, rationalizing his racist ideology and his ambition to learn the Dark Arts as "sensible"" (Lamb, 2015). The use of the word Mudblood, "a really foul name for someone who is Muggleborn" (Rowling, 1998), by Draco Malfoy and other wizards "who think theyre better than everyone else because they're what people call pure-blood" (Rowling, 1998) is an insult and it is clear by the way the other characters in the books react to the word. It is a word used to demean Muggle-borns and belittle their abilities and right to exist in the magical world. The only reason for it being that the pure-bloods believe that they are superior and likely fear that their magic is being taken beyond them to those who are not worthy of it.

Xenophobia is a fear or dislike of the customs, dress, etc., of people who are culturally different from oneself. The term can be applied to the views of pure-bloods in Harry Potter. They believe they are better than Muggles and Muggle-borns, but it is clear that even the wellmeaning wizards do not understand the culture of Muggles. This would be a natural progression from not understanding the Muggles, to fearing the culture that the pure-blood wizards do not understand, and then acting out against it; and there are many examples in the novels. One such example is the Black family that lives in a house surrounded on either side by Muggles in the heart of London, yet when Andromeda Black married a Muggle-born, she was struck off the family tree and disowned. The Black's house-elf clearly hates Muggle-borns and half-bloods, referring to members of the Order of the Phoenix, a secret society created to fight Voldemort and his followers, as "Mudbloods and traitors and scum" (Rowling, 2003), while the late Walburga Blacks moving portrait literally screams, "stains of dishonor, filthy half-breeds, blood traitors, children of filth" (Rowling, 2003) at the members, making it clear how this pure-blood family loathed their neighbours. There exist numerous real events which parallel the series' exploration of this pure-blooded perspective of fearing and hating different cultural groups.

Perhaps the most famous example of racism and xenophobia in modern history is manifested through Hitler and his regime in Germany. Hitler had an ideal race of people with which he wanted to populate the world, and Voldemort had very much the same idea. A contributing factor to the rules they create both are based in the fear of their ideal race dying out. In fact, 
they both differentiated based on blood status (Wente, 2015). The Slytherin house, one of the four houses that students at Hogwarts School of Witchcraft and Wizardry can be placed into for the duration of their studies, is especially concerned about blood purity, with members of the house, Draco in particular, bragging about blood status and shunning those not from pure-blood families. As early as the first novel, Draco tells Harry that Hogwarts should "keep it in the old wizarding families" (Rowling, 1997). Voldemort, who is a Slytherin as well, desires "to establish a pure-blood ruling class and subject Muggles to hard labor" (Wente, 2015). Hitler thought he could "purge the German blood pool" (Wente, 2015) because he saw an Aryan society as perfect and thought that the Jewish people were corrupting their country. Both of these leaders sought to purify their worlds and wished to create a lasting change to their cultures.

The most prominent way that Voldemort tried to affect change for future generations is by changing the curriculum at Hogwarts. Originally, Muggle Studies was an orientalist class about how Muggles go about their lives without magic and was taught from "the wizarding point of view" (Rowling, 1999), which was the reason Hermione, a Muggle-born, took the class. It would be an important class if it was not taught in such a biased fashion. It can be assumed that Muggle Studies was not very insightful into the Muggle world, as Arthur Weasley likely took the class and he still has very little grasp on Muggle culture. To create biased views in the wizarding community of the future; because of Voldemort's influence, Muggle Studies becomes a mandatory class that teaches "how Muggles are like animals, stupid and dirty, and how they drove wizards into hiding by being vicious toward them, and how the natural order is being re-established" (Rowling, 2007) by Voldemort's rule. Muggle Studies in a Voldemort controlled world taught students to hate and fear Muggles as much as Voldemort and his pure-blood followers do, corrupting their views with the intent of turning them into future Death Eaters (Volde- mort's followers). This mimics the way that anti-Semitism was taught in German schools. Hitler used schools to regulate the knowledge of the youth in Germany, molding the kids into future Nazis through class content and youth groups (Wente, 2015). Both Hitler and Voldemort wished to remake the future of their respective worlds into what they viewed as pure and strong, and both of them did this by targeting the education of the future members of those worlds: children.

The Harry Potter series shows the nuances of racism and how such nuances are manifested by people without the readers having to experience it themselves. The novels manage to parallel the unpleasant reality of racism and the power it holds over populations. Through the inclusion of Muggles, and especially Muggle-born wizards, the books are used as a cultural commentary on what happens in the real world to real people. The novels instill an understanding of how racism can climax in the worst way possible: through the deaths of Muggles, along with many characters that we care about who are fighting to protect them; however, the readers never have to experience racism themselves. The ambiguity of many of the characters in the novels and indeed the ambiguous racist acts themselves help "to illustrate for children the nuances of right and wrong, good and evil" (Rosado, 2015) by not allowing them to be black and white concepts in this series. Showing the humanity of clearly racist characters such as Voldemort and Draco Malfoy, along with the hidden racist past of Dumbledore, tears apart what the readers "[assume] about characters based solely on behavioral patterns and their resultant expectations" (Rosado, 2015). Ideally, the lack of clear borders between blatant and subtle racism, along with the morally ambiguous characters, will help teach the readers of these novels that racism is a real problem that comes in many forms. As well as the idea that getting a better, and truer, understanding of a culture is the best way to go about avoiding these negative results, whether those results are the Orientalism of the 
pro-Muggle wizards or the open xenophobia of Voldemort, his followers, and millennia of pureblood wizards. Translating this lesson into the real world helps promote a better understanding of how to avoid racially charged acts.

The Harry Potter novels address racism in two forms throughout the series, Orientalism and xenophobia. The continuous spectrum between good and evil is demonstrated through the ambiguous nature of the subtle and obvi- ous forms of racism used by both moral sides in the novels. This all comes together to show readers that racism is not inherently linked with evil forces both fictional and in real life, but it can also be perpetuated by characters that are stereotypically good. Ideally, this will lead to the readers not tolerating racism in the future and understanding the different ways that oppression can be enacted on groups of people.

\begin{abstract}
About the Author
I am a student at the University of Waterloo, where I am double majoring in Knowledge Integration and Anthropology with a minor in Psychology. My interests lie in exploring people from different angles. I wrote this submission for a class, taking advantage of my professor letting me combine the subject of the Harry Potter books with my own interests in anthropology. I wanted to publish with JIRR because I believe there is a huge benefit to looking at something with different points of view, and the journal celebrates that.
\end{abstract}




\section{Bibliography}

Lamb, H. (2015). The Wizard, the Muggle and the Other: (Post) Colonialism in Harry Potter. In C. Konchar Farr, A Wizard of Their Age. Albany: State University of New York Press.

Rosado, T. (2015). The Generation(s) of Harry Potter: The Boy Wizard and His Young Readers. In C. Konchar Farr, A Wizard of Their Age. Albany: State University of New York Press.

Rowling, J.K. (1997). Harry Potter and the Philosopher's Stone. Scholastic Press.

Rowling, J.K. (1998). Harry Potter and the Chamber of Secrets. Scholastic Press.

Rowling, J.K. (1999). Harry Potter and the Prisoner of Azkaban. Scholastic Press.

Rowling, J.K. (2000). Harry Potter and the Goblet of Fire. Scholastic Press.

Rowling, J.K. (2003). Harry Potter and the Order of the Phoenix. Scholastic Press.

Rowling, J.K. (2005). Harry Potter and the Half Blood Prince. Scholastic Press.

Rowling, J.K. (2007). Harry Potter and the Deathly Hallows. Scholastic Press.

Said, E. (1978). Orientalism. London and Henley: Routledge \& Kegan Paul Ltd.

Wente, S. (2015). The Making of a New World: Nazi Ideology and Its Influence on Harry Potter. In C. Konchar Farr, A Wizard of Their Age. Albany: State University of New York Press. 